\title{
Cuidado paterno e desenvolvimento infantil ${ }^{*}$
}

\author{
Carina Nunes Bossardi ${ }^{l}$ \\ Mauro Luís Vieira ${ }^{2}$ \\ Universidade Federal de Santa Catarina
}

Ao abordar temas referentes ao desenvolvimento humano deve-se considerar os contextos históricos, sociais e culturais que constituem os cenários em que tal desenvolvimento ocorre. Fala-se a respeito da interação biologia e cultura para compreensão dos fenômenos. Este trabalho preocupa-se em investigar questões que envolvem os relacionamentos familiares e os contextos de desenvolvimento. Partindo de uma visão evolucionista discute as diferenças e semelhanças entre os papéis que homens e mulheres assumem frente a parentalidade e a criação dos filhos. As novas configurações familiares, o papel das crenças parentais e a participação paterna são discutidas com relação à influência no desenvolvimento infantil e no comportamento materno e paterno. Todas as reflexões alertam para a importância da compreensão de como está se configurando a paternidade, o papel do pai e a instituição familiar e garantem o caráter interacionista para compreensão do fenômeno, já que envolvem aspectos biológicos, evolucionistas e culturais proporcionados pelo contexto.
The study of human development should consider the historical, social and cultural contexts that constitute the scenery where the development occurs. It regards the interaction among biology and culture to understand the phenomena. This article is concerned about the investigation of questions that involve the family relationships and the contexts of development. It is based on the evolutionary perspective and it argues about the differences and similarities among the roles that men and women assume as parents and to bring up a child. The new family configurations, the role of the parental beliefs and the paternal participation are argued with relation to the influence in the infantile development and the maternal and paternal behavior. All the reflections alert to the importance of understanding how paternity is being configured. The father's role and the family institution guarantee the interactionist character to understand the phenomenon, considering they involve biological, evolutionist and cultural aspects provided by the context.

\footnotetext{
" Paternal care and child development

' Psicóloga, mestranda do Programa de Pós-Graduação em Psicologia, Universidade Federal de Santa Catarina (carinabossard@yahoo.com.br).

${ }^{2}$ M.L. Vieira é Professor Doutor. Endereço para correspondência: Universidade Federal de Santa Catarina, Departamento de Psicologia, Campus Universitário, Florianópolis, SC, 88040-900 (mviera@cfh.ufsc.br).
} 
Palavras-chave: Psicologia Evolucionista - Contexto de desenvolvimento - Cuidados parentais - Papel paterno
Keywords: Evolutionary psychology

- Developmental context - Parental cares - Paternal role

\title{
Introdução
}

\begin{abstract}
A o abordar temas referentes ao desenvolvimento humano, não se pode deixar de percorrer algumas discussões realizadas a cerca, dos contextos históricos, sociais e culturais que constituem os cenários em que tal desenvolvimento ocorre e, para tanto, é necessário também sistematizar a compreensão que se tem sobre as pessoas que estabelecem interações dentro
\end{abstract} desses contextos, ou seja, como está configurado o sistema familiar.

Com este interesse, muitas pesquisas foram realizadas objetivando investigar características que podem exercer influência sobre o desenvolvimento infantil (ALVARENGA \& PICCININI, 2007; KELLER, 2007; RUELA, 2006; PIOVANOTTI, 2007; SEIDL DE MOURA et al, 2004; SACHETTI, 2007; LORDELO et al, 2006). Recentemente surgiram esforços e questionamentos mais amplos que podem vir a contribuir com este conhecimento e aborda-se a respeito do impacto das crenças e práticas maternas e das atitudes e envolvimento parentais para o desenvolvimento humano.

Uma preocupação dos pesquisadores é investigar questões que envolvem os relacionamentos familiares e os contextos de desenvolvimento, influenciando e sendo influenciados pela cultura e por fatos sócio-históricos. Começa a se delinear no cenário científico estudos voltados para a compreensão do papel da figura paterna para o desenvolvimento infantil. Segundo Silva (2003) a concepção do que é ser pai no atual cenário familiar está mudando, de um papel tradicional, de provedor do sustento econômico, atuando indiretamente no desenvolvimento infantil, para um pai mais ativo nos cuidados com o filho. Assim caracteriza-se o crescente interesse em se estudar o comportamento paterno.

Neste artigo de atualização pretende-se percorrer temas que aparecem relacionados ao desenvolvimento infantil, à existência da função paterna e sua influência no cuidado e educação das crianças. Segundo Piccinini e colaboradores (2001) diversas perspectivas podem ser adotadas para abordar os temas que envolvem o desenvolvimento infantil, bem como o sistema de crenças e valores parentais.

Os aspectos aqui abordados terão como base a perspectiva evolucionista para compreensão do desenvolvimento humano. Segundo tal perspectiva, as diferenças e semelhanças entre os papéis que homens e mulheres assumem frente a parentalidade e a criação dos filhos, podem ter ume explicação evolutiva. Essas explicações têm origem desde a escolha do parceiro, 
passando pela história reprodutiva de homens e mulheres até as funções assumidas pela mulher durante e depois da gestação, que se diferenciam das funções exercidas pelo companheiro homem (SILVA \& BRITO, 2005).

A Psicologia Evolucionista, por meio de uma perspectiva interacionista, propõe que os fenômenos sejam compreendidos levando em consideração o nível ontogenético e filogenético da espécie humana, ou seja, estudá-los de um modo mais abrangente, onde o ontogenético refere-se ao desenvolvimento do ser humano a partir de seu nascimento e o filogenético corresponde ao desenvolvimento da espécie, trazendo, portanto, explicações de uma história evolucionista (VIEIRA \& PRADO, 2004).

Parte-se do princípio de que o modo como pais e mães irão desempenhar suas funções e responsabilidades com o lar e com as crianças vai depender de fatores biológicos e culturais em constante interação e tanto um quanto o outro irão desenvolver comportamentos específicos no cuidado com os filhos e, para acessar tais comportamentos utiliza-se os conceitos de investimento parental.

\section{Investimento parental e cuidados parentais}

Em termos da perspectiva evolucionista, parte-se do pressuposto que existem dois níveis de análise que devem ser considerados para se compreender um comportamento ou um sistema comportamental (VIEIRA et al., 2009). Um deles são os fatores causais próximos (variáveis que modulam o comportamento durante a ontogênese). Outro são os fatores causais últimos, ou seja, que implicações as estratégias comportamentais (intencionais ou não) tem em relação a sobrevivência da indivíduo e dos seus descendentes (aptidão direta) ou de membros aparentados (aptidão inclusiva), tendo por consequencia a perpetuação da espécie.

Especificamente no caso dos cuidados parentais, os fatores causais próximos seriam as condições psicológicas, culturais e sociais que modulam a forma com que mães e pais se engajam no cuidado, proteção e estimulação dos seus filhos. Em termos de consequência para a sobrevivência, deve-se levar em conta também os fatores ecológicos. Ou seja, dependendo das condições ecológicas presentes, diferentes estratégias podem ser utilizadas. Por exemplo, em condições adversas, em função de vários fatores (dificuldade de encontrar alimento, disputa por espaço e parceiros para acasalamento), algumas estratégias podem ser mais eficientes do que outras que são funcionais em ambientes mais estáveis, que são denominadas de estratégias " $k$ " e " $r$ " (GUERRA, 2003). Portanto, em função dos diferentes níveis de análises, é importante deixar claro qual é o domínio que se está estudando. Nesse sentido, é importante utilizar conceitos diferenciados para cada nível. 
Embora sejam separados, isso não significa que sejam independentes. Podem sim ter influência um sobre o outro.

Por outro lado, é importante destacar outra divisão em relação aos cuidados parentais, que são os cuidados diretos e indiretos (HEWLETT, 1992; GUERRA, 2003). No primeiro caso podemos mencionar o contato físico e a amamentação. Já no segundo, a proteção contra predadores e ameaças do ambiente externo, bem como o fornecimento de condições materiais e de alimentação. Essa divisão é importante na medida em que auxilia na compreensão de que existem diferentes formas de expressar o cuidado parental. Pode-se dizer que no caso da espécie humana, nos primórdios da evolução o cuidado direto da mãe teve papel importante na sobrevivência da prole. No entanto, em muitas sociedades atuais industrializadas, existem várias formas indiretas de cuidado (KELLER, 2007). Ou seja, os bebês passam menos tempo em contato com as mães e estas investem de modo indireto nos filhos, como por exemplo, trabalhando para dar melhores condições de vida à sua família. Nesse sentido, existe uma complexa relação entre duração do aleitamento e o cuidada materno (QUINLAN et al., 2003).

De modo geral, pode-se dizer que comportamentos, responsividade ou cuidados parentais dizem respeito as ações que pais e mães tem em relação aos filhos (VIEIRA et al., 2009). Fazem parte dessa categoria, dar comida, trocar fraldas, proteger, estimular, educar, etc. Por outro lado, a teoria do investimento parental preconiza que certos comportamentos aumentarão as chances de sobrevivência da prole, mas ao mesmo tempo, diminuirão a probabilidade dos genitores se engajarem na produção de uma nova progênie (TRIVERS, 1972; VIEIRA et al., 2009). Também se deve destacar que existe relação entre o investimento parental e a seleção sexual. Isso significa dizer que o sexo que mais investe na prole é o mais exigente quanto à escolha do parceiro, enquanto o sexo que investe menos investe compete mais ativamente para obter membros do sexo oposto e garantir o sucesso reprodutivo (BORRIONE \& LORDELO, 2005; KRIEGMAN, 1999).

Assim, os modos de investimento parental irão variar entre homens e mulheres. Segundo Keller e Chasiotis (2007) a forte ligação entre a mãe e seus filhos, em termos filogenéticos, se dá em função da certeza da maternidade (a exemplo do que acontece com outros mamíferos, a gestação é materna) e das suas consequiências, como por exemplo, amamentação ${ }^{3}$. O pai, por sua vez, não tem certeza da paternidade e pode investir mais ou menos em função deste fato. Além da explicação evolucionista, tem-se o fato de que o investimento no

${ }^{3}$ Deve-se destacar que essa afirmação é entendida como pressuposto para a espécie e não para indivíduos de modo específico; a intensidade e a forma dos cuidados vão depender de fatores, tais como história de vida, aspectos psicológicos, sociais, ecológicos e culturais, por exemplo, poderiam explicar as diferenças individuais. 
cuidado com a criança variará em diferentes contextos de acordo com a cultura e com os custos envolvidos (TOKUMARU \& BERGAMIN, 2005). Dessa forma, para a teoria evolucionista o investimento parental envolve gasto de energia e, para tanto, há variações entre fêmeas e machos na quantidade de investimento despendido para o acasalamento (oportunidades reprodutivas) e para o cuidado com a prole (cuidado parental), conforme as características de desenvolvimento dos filhotes e das condições ecológicas (LORDELO et al., 2006). Uma das características típicas da espécie humana é o longo período de desenvolvimento e a consequente dependência física e psicológica da criança em relação aos adultos. Nesse sentido, os cuidados dos adultos, que geralmente são fornecidos pelos genitores, se fazem necessários,

Os cuidados parentais são entendidos como sistemas de cuidado a que o indivíduo é exposto durante os primeiros anos de vida e que têm conseqüências importantes no desenvolvimento infantil. A mãe, geralmente, é a figura identificada como referência para o cuidado e interação com o bebê. Os bebês apresentam um conjunto de características que os capacitam para os primeiros contatos e trocas com os membros da cultura, como por exemplo, o choro e outros comportamentos que despertam respostas nos adultos (GUERRA, 2003; SEIDL DE MOURA \& RIBAS, 2004). Por outro lado, a visão da maternidade vem se modificando ao longo do tempo. Atualmente, a mãe deixa de ser identificada como figura única na vida de uma criança e o pai começa a estar presente nas discussões (BANDEIRA, GOETZ et al., 2005).

Assim, as funções parentais sofrem a influência de processos biológicos, na medida em que possuem comportamentos universais que evoluíram ao longo da filogênese, mas também se modificam na interação com a cultura. Tais considerações permitem abordar a existência de diferenças no comportamento parental de homens e mulheres.

\section{Diferenças entre homens e mulheres com relação ao comporta- mento parental}

Para compreender as atitudes parentais e como o comportamento maternal e paternal humano foi selecionado no decorrer do processo de evolução, ressalta-se mais uma vez o papel da interação biologia-cultura, enfatizando que as diferenças perpassam fatos como a escolha de um parceiro e a estratégia reprodutiva de homens e mulheres e as diferenças de gênero colocadas pelo contexto cultural.

A espécie humana caracteriza-se pelo alto investimento parental e esse investimento é definido pela maior ou menor quantidade de cuidado biológico e/ ou psicológico dispensado à prole e as condições ecológicas que os pais vivenciam, 
influenciam nas decisões de investimento parental, as quais se expressam na prevalência de certos estilos de cuidado e diferenças no investimento dispensado à prole entre fêmeas e machos (LORDELO et al., 2006). A fêmea, dado o maior investimento prévio na produção de gametas, gestação e amamentação, tende a investir mais em esforço parental, enquanto os machos tendem a investir mais em esforço reprodutivo, mas esse esforço reprodutivo, dentre os humanos não estaria apenas ligado a busca de parceiro, mas também, a manutenção da relação com a nova parceira. Ambos os sexos podem prover cuidados, ou desejar fornecer cuidados às crianças e este ato pode servir como atrativo para estabelecer e manter relações (TOKUMARU \& BERGAMIN, 2005).

Biologicamente, as mulheres apresentam escolhas sexuais mais seletivas e é o sexo que mais investe nos descendentes, já que há um grande gasto de energia na produção de óvulos, além da gestação e da lactação. Enquanto para os homens o investimento é menor, pois seu sucesso reprodutivo é determinado pelo número de inseminações. Em função disto, o investimento na maternidade pelas fêmeas é maior do que na paternidade pelos machos e, em cada período da criação dos filhos, em que as fêmeas dedicam cuidados cada vez maiores, se intensificam as diferenças entre o investimento parental de pais e mães (SILVA \& BRITO, 2005).

Por outro lado, pesquisas têm mostrado que hormônios relacionados ao cuidado materno, como a ocitocina e a prolactina também podem estar relacionados ao comportamento paterno e, que, além disso, este último pode sofrer mudanças neuroendócrinas ativadas por estímulos vindos do contato com as fêmeas e com os filhotes (VIEIRA et al., 2009). Estudos com animais demonstram que o cuidado paterno pode ser identificado mesmo entre primatas não humanos, na medida em que os machos dirigem cuidados como carregar, sustentação e proteção para sua própria prole. Esses cuidados devem resultar em benefício da sobrevivência. A certeza da paternidade, ou seja, o parentesco com o filhote faz com que o cuidado paterno ocorra em maiores proporções. A cópula com a fêmea em dias de fertilidade e/ou a permanência com ela durante um período maior de tempo, permitem que esta certeza seja identificada e que os comportamentos de cuidados paternos aumentem (BUCHAN et al., 2003).

No decorrer da evolução humana houve uma intensificação do cuidado maternal, assim como a introdução dos cuidados paternais. Já se sabe que a mulher é preparada biologicamente para gerar e amamentar, no entanto, são as circunstâncias sociais que indicarão o modo como ela cuidará de seu bebê, ou seja, o investimento materno pode sofrer influências culturais e não somente ser determinado pelo fato da maternidade. "Para cada sociedade existe um papel que deve ser desempenhado pelas mães no cuidado de seus filhos que são disseminadas pelas regras culturais" (SILVA \& BRITO, 2005; p. 266). 
Transformações sociais como a inserção da mulher no mercado de trabatho e a possibilidade de controle de sua reprodução, levou a mulher a se dedicar mais a seu bem-estar, segurança econômica e realização profissional em relação a sua função materna. Assim, há algum tempo, a visão da maternidade vem se modificando e as funções parentais sofrem a influência de processos biológicos, na medida em que possuem comportamentos universais que evoluíram ao longo da filogênese, mas também se modificam na interação com a cultura (GOETZ \& VIEIRA, 2008).

Desse modo, a cultura também exerce sua participação nos comportamentos paternos e maternos, influência essa que pode ser explicada desde a inserção da criança em um contexto de desenvolvimento. As crianças aprendem e desenvolvem habilidades na interação com o outro. $O$ papel de gênero, ou seja, o que é ser menino e menina, vem se definindo a partir destas interações e desde então, são encontradas diferenças nas funções de homem e mulher, baseadas tanto na herança biológica quanto na cultural.

Culturalmente, de acordo com Rogoff (2005) [...] "as crianças desenvolvem papéis diferenciados de sua comunidade a partir de modelos apresentados na vida cotidiana e do estímulo ou desestímulo de atividades relacionadas a esses papéis" (p. 68). Meninos e meninas são estimulados pela comunidade cultural a desempenhar funções e papéis diferentes. As meninas são geralmente encarregadas de trabalhar em casa, fazer companhia à mãe, cuidar de um irmão, enquanto os meninos tem permissão para brincar na rua e trabalhar mais longe na companhia de seus pares. O comportamento de cuidar de outras crianças por parte das meninas pode estar relacionado ao fato de as mães apresentarem mais habilidades na interação com bebês quando comparadas com os pais (ROGOFF, 2005).

As recentes transformações surgidas nas últimas décadas sobre família e também sobre desenvolvimento infantil, retratam a necessidade de se redefinir alguns conceitos e papéis que envolvem a maternidade, a paternidade e, consequentemente, a família e seus papéis para o desenvolvimento das crianças. A modernização da sociedade é apontada como uma das causas principais para as mudanças de um modelo tradicional de família, para um modelo de famílias monoparentais, de recasamentos, entre outros. Segundo dados do IBGE (2006) entre 1995 e 2005 o número de famílias que eram chefiadas por mulheres cresceu $35 \%$ e esse crescimento foi maior em Santa Catarina e no Mato Grosso. O aumento vem ocorrendo mesmo nas famílias onde há a presença do cônjuge, mas ainda é fortemente representada nas famílias onde não há cônjuge.

Com isso, um novo perfil de mãe e também de pai começa e ser delineado dentro do contexto familiar e parece ser um desafio da atualidade configurar as relações familiares, ou seja, as interações dos pais (pai e mãe) com os filhos e com eles próprios. Assim, parece que envolvimento parental vai depender das 
questões de parentesco e consangüinidade, que buscam a perpetuação da espécie e também de outros fatores como o número de filhos e as condições sociais e econômicas. Dada as mudanças relativas ao contexto familiar, a paternidade começa a ser melhor definida e o envolvimento paterno passa a ser estudado e determinado em termos de quantidade, conteúdo e qualidade. Estudos que buscam configurar as funções paternas na família e no desenvolvimento infantil demonstram um aumento no envolvimento paterno, no sentido em que existe um movimento de maior participação dos pais no cuidado da criança (SILVA \& PICCININI, 2007; VIEIRA et al., 2009).

Mais uma vez evidencia-se a participação da cultura na definição de papéis de gênero e também nos comportamentos maternos e paternos, o que permite compreender as diferenças existentes por meio de uma visão de interação biologia-cultura. Desse modo, pode-se definir que os papéis sociais desempenhados por homens e mulheres podem ser compreendidos a partir destas influências.

\section{Família e os papéis sociais desempenhados por homens e mulheres}

A família deve ser vista como um grupo específico em desenvolvimento, inserido em um contexto cultural que pode causar impacto sobre o desenvolvimento de uma criança. Para compreender como as famílias funcionam é preciso refletir sobre suas transformações, modo de funcionamento, funções que lhe são atribuídas e ainda os papéis que são exercidos por cada membro participante, de acordo com o contex to histórico e cultural (DESSEN, 2000).

A estrutura familiar vem passando por transformações (constituição de famílias monogâmicas, divórcios, recasamentos) e os papéis maternos e paternos são multidimensionais e complexos, na medida em que pais e mães desempenham papéis diferenciados dependendo dos contextos culturais e da função familiar que ocupam. Para compreender como a família funciona e descrever os papéis maternos e paternos dentro da dinâmica familiar é necessário desenvolver métodos que estejam de acordo com a diversidade dos contextos cultural, histórico, social, econômico e intergeracional no qual as famílias estão inseridas (CERVENY, 2002).

O número de lares chefiados por mulheres está crescendo, revelando que as mulheres estão ocupando cada vez mais, no contexto atual das famílias brasileiras, o papel de provedoras do sustento da família. Sendo assim, a função paterna vem se alterando, de um papel tradicional de provedor do lar, para o de homem mais participativo, tornando-se pai mais presente, atuando diretamente no que se refere ao cuidado com os filhos (PERUCCHI \& BEIRÃO, 2007). 
Cerveny (2002) ao discorrer sobre a família e seu processo evolutivo (ontogênese) refere os avanços da comunicação, da tecnologia, da globalização, das questões de gênero, da espiritualidade, da biotecnia e do aumento populacional como sendo as mudanças pelas quais a família passa nas últimas décadas.

Esta questão alerta para a necessidade de realizar pesquisas que tenham como objetivo a investigação desta temática, levando em consideração a diversidade cultural existente mesmo dentro de um contexto social determinado. Dessen (2000) alerta para o fato de que, recentemente, as questões sobre família estão sendo apontadas como uma das tendências futuras na pesquisa em Psicologia. Neste sentido, pode-se incluir também o interesse pela temática da paternidade. Goetz e Vieira (2009), ao citar Lewis e Dessen (1999), ressaltam o desequilíbrio nas pesquisas, na medida em que a mãe é tida como alvo principal dos pesquisadores e reconhecem a importância de se tentar compreender igualmente o papel do pai, dada a complexidade das relações familiares, indicando com isso a necessidade de ampliar as pesquisas na área.

Em uma pesquisa nas bases de dados Medline, CINAHC e PsycINFO, entre os anos de 1983 a 2003, Magill-Evans, Harrison, Rempel e Slater (2006) realizaram uma revisão sobre intervenções com pais de crianças e revelaram que a interação pai-bebê tem sido considerada nas pesquisas e que assim como as intervenções com as mães podem promover efeitos efetivos para o desenvolvimento das crianças, as intervenções abordando os pais e sua interação com as crianças também podem promover efeitos positivos. Foi concluído neste estudo, que embora pesquisas recentes tenham indicado que o pai também contribui para o desenvolvimento da criança, pouco se conhece sobre os tipos de intervenções com o pai que possam estimular e desenvolver responsividade paterna e interação pai-criança de qualidade.

\section{Papel paterno e paternidade}

Mudanças nas configurações familiares geram redefinições nas atribuições e responsabilidades de cada progenitor. $O$ papel do pai e a função paterna começam a ser focalizados e reelaborados. Tais modificações perpassam questões como: o modelo e a experiência do que é ser pai, o papel masculino, crenças, valores e resignificações histórico-culturais. Inicia-se um processo de mudança nos papéis dos membros familiares e nos papéis atribuídos ao pai que estão associados a padrões culturais, ou seja, sobre o que se considera hoje ser um bom pai. O pai passa a ser visto não mais como somente o provedor, mas como importante no desenvolvimento infantil (BANDEIRA et al., 2005). 
O padrão ideal que vem sendo constituído é de um pai participativo e envolvido com a família e com o filho. Este fato demarca um aumento nas funções paternas que agora inclui o vínculo com a criança e a responsividade no cuidado parental, mas não chega necessariamente em uma igualdade com as tarefas da mãe (BANDEIRA et al., 2005; FLECK \& WAGNER, 2003).

A redefinição de responsabilidades e papéis de homens e mulheres está modificando também as crenças e atitudes sobre quais funções espera-se que pais e mães desempenhem no contexto familiar (SILVA \& PICININNI, 2007). Quando a mãe tem um emprego externo, os homens são chamados às falas e a responsabilidades maiores dentro do lar. Um trabalho fora de casa diminui, indubitavelmente, o contato das mães com seus filhos, concorrendo para a presença de um "substituto". Mas de fato isto acontece ainda em escala bem menor que a esperada ou desejada (JABLONSKI, 1998).

O tema que envolve o papel do pai e sua importância para o desenvolvimento infantil tem sido alvo de estudo pela Psicologia. As recentes transformações surgidas nas últimas décadas sobre família e também sobre desenvolvimento infantil, retratam a necessidade de se redefinir alguns conceitos e papéis que envolvem a maternidade, a paternidade e, consequentemente, a família e seus papéis para o desenvolvimento das crianças.

Ao discorrer sobre a função da família e o cuidado parental para o desenvolvimento infantil, Vieira e colaboradores (2009) referem o papel do pai como significativo para promover um contexto propício para o desenvolvimento dos filhos. Estudos com animais podem ser indicativos do cuidado paterno, na medida em que tem sido demonstrada uma capacidade do pai em fornecer cuidados diretos e interagir afetivamente com os filhos, indo além da capacidade de fornecer cuidados indiretos (defesa e sustento). Dessa forma, o estudo do comportamento paterno deve buscar compreender a história filogenética da espécie interatuando com aspectos do contexto em que este ocorre.

Segundo Wagner e colaboradores (2005) em muitas famílias já se percebe divisão de tarefas educativas e de organização do dia-a-dia da família, mas o que se encontra atualmente são famílias com diferentes configurações e estruturas, coexistindo modelos familiares mais tradicionais (visão do pai como provedor e mãe, cuidadora), outros em que maridos e esposas dividem tarefas domésticas e educativas e ainda mulheres como as principais mantenedoras do lar, assumindo todas as responsabilidades dentro da família. Em um estudo, realizado, com 100 famílias da região de Porto Alegre, as autoras citadas procuraram avaliar a participação do pai e da mãe no desempenho de tarefas e as suas responsabilidades diárias junto aos filhos. Os resultados revelaram a coexistência de dois tipos de estrutura familiar, ou seja, o grupo em que a mãe é a principal responsável pelas tarefas que envolvem a criação e educação dos filhos e o grupo em que há uma divisão de tarefas entre o pai e a mãe. 
Silva e Piccinini (2007) demarcam que pouco se sabe sobre como os pais estão vivenciando tais mudanças, como se avaliam e que sentimentos possuem com relação à paternidade. Para isso, em um estudo, buscaram compreender os sentimentos relacionados à paternidade e o envolvimento paterno de pais casados e com apenas um filho em idade pré-escolar. Os resultados obtidos por meio das três entrevistas realizadas, sugeriram satisfação com a paternidade e relatos de bom relacionamento com os filhos. A interação desses pais com seus filhos incluía cuidados básicos e responsabilidade dividida entre pai e mãe e a acessibilidade desses pais para os filhos apareceu como influência crucial sobre sua interação com as crianças.

Na França, conforme Devreux (2006) modificações jurídicas recentes tendem a igualar os direitos do pai e da mãe para com os filhos. Devido ao grande número de separações conjugais e ao lançamento das mulheres no mercado de trabalho, a visão do pai provedor e da mãe guardiã do lar e educadora dos filhos não apresenta conformidade com a realidade atual. O pai se destaca e reivindica maiores participações com relação aos filhos.

No Canadá, transformações no plano social e jurídico também demarcam as novas configurações familiares e no papel de pai e mãe (TAHON, 2006). A luta pela igualdade das sexualidades e a utilização da inseminação artificial leva a formulação de leis e de projetos parentais. Neste país, desde o ano de 2000 , uma lei permite a casais do mesmo sexo usufruírem dos mesmos direitos sociais garantidos aos heterossexuais e também são realizados acordos proporcionando às famílias a terem filhos a partir de uma terceira pessoa, ou seja, um doador. Com relação ao projeto parental são constatadas diferenças entre homens e mulheres, sendo que elas, estando em casal ou a sós, podem contar com o recurso da procriação assistida, em contraste com eles que não podem usufruir de tal recurso em nenhuma circunstância (TAHON, 2006).

Em um estudo realizado com famílias gregas, Kassotaki (2000) identificou diferenças no envolvimento do pai grego com a família e com as tarefas de cuidados da criança, durante o seu primeiro ano de vida, dependendo do contexto em que os pais estavam inseridos, da sua escolaridade e nível sócioeconômico. Pais provenientes de áreas urbanas com nível educacional e sócioeconômico altos se envolviam mais nas atividades de preparação antes e após o nascimento de um bebê e o envolvimento em brincadeiras e em uma variedade de tarefas rotineiras de cuidados da criança do que os pais de áreas rurais de nível educacional e sócio-econômico baixos.

De acordo com Renon (2009) a convivência familiar representa importante aspecto dos direitos humanos, visto que sem ela, a formação e o desenvolvimento da pessoa humana estariam prejudicados. Especificamente no Brasil, desde a Constituição da República de 1988, a família antes patriarcal passa a existir também a partir do reconhecimento do vínculo afetivo. 
É entendida como responsável pelo desenvolvimento integral da criança, no sentido de prepará-las para as suas responsabilidades no convívio social e que vincula as pessoas que a compõem em razão de laços de sangue ou não. O Estatuto da Criança e do Adolescente também ressalta a importância da vida em família.

À paternidade e à maternidade são atribuídas responsabilidades de prover à prole cuidado e suporte afetivo e material necessários. O pai, de autoridade patriarcal passa a ocupar a função de participante da organização familiar e com direito/dever, nem sempre reconhecido, de participar da formação, convivência afetiva e desenvolvimento dos filhos. Na visão jurídica a paternidade é estabelecida no momento em que o pai reconhece e concede seu nome a seu filho. Por meio do registro civil surgem direitos e obrigações de sustento, guarda e educação (RENON, 2009).

Um dos conceitos de família, a define como unidade grupal onde se desenvolvem três tipos de relações: a aliança (casal), a filiação (pais/filhos) e a consangüinidade (irmãos). A afetividade foi inserida como mais um elemento de condição para existência de um sistema familiar, que regulamentado pela Constituição da República de 1988, é definido pelo casamento, a união estável e a família monoparental (RENON, 2009). Enquanto a família permanece unida, os cuidados com os filhos são exercidos em igualdade de condições. Quando os pais se divorciam, as crianças geralmente passam a conviver com um só genitor. Apesar das diversas modalidades de guarda de filhos, dados de 2007 apontam que ainda há hegemonia das mulheres na guarda dos filhos menores de idade, o que retrata a importância de informar aos pais a necessidade da convivência familiar e sobre os reflexos que seus atos podem causar na vida dos filhos. No sistema jurídico a paternidade aparece como fonte de investigação, para determinar através do exame genético a verdade sobre o pai, já que mãe é certa e pai é incerto (RENON, 2009).

Todas estas reflexões alertam para a importância da compreensão de como está se configurando a paternidade, o papel do pai e a instituição familiar e garantem o caráter interacionista para compreensão do fenômeno, já que envolvem aspectos biológicos, evolucionistas e socioculturais. Através de pesquisa realizada no Brasil, mais especificamente na cidade do Rio de Janeiro, as atividades relacionadas ao investimento parental relativas aos cuidados primários como amamentar, levar ao médico, vacinar, cuidar da alimentação, entre outros foram significativamente mais relatadas pelas mães (BANDEIRA, 2009). Para os participantes desse estudo, as mulheres continuam sendo as principais cuidadoras. Entretanto, a preocupação com os cuidados é maior entre os homens, o que a faz inferir que talvez isso indique um processo de mudança, no sentido em que os homens já estejam tendendo para uma maior participação nessa tarefa. 
Saraff e Srivastava (2009) referem a paternidade como um fenômeno social importante para a infância e que portanto, o envolvimento paterno em termos de participação em atividades, frequiência dessa participação e no cuidado com as crianças, tem sido investigado por pesquisadores. Em uma análise entre pais indianos, os resultados indicam que o envolvimento paterno nos cuidados com a criança pode ser determinado pela percepção sobre a paternidade e pelas expectativas em relação ao seu papel. Os fatores sócio-econômicos também têm sido examinados como influentes no envolvimento e a importância deste assunto implica na criação de programas e intervenções que possam promover atitudes e participação paterna.

\section{Considerações finais}

O interesse pelo estudo do papel do pai em relação aos cuidados infantis tem raízes em alguns acontecimentos sociais como o movimento feminista, entrada das mulheres no mercado de trabalho, aumento no número de divórcios, os quais exigiram uma nova definição dos papéis sexuais e da constituição familiar. Apesar destes aspectos sociais não se pode deixar de considerar a influência dos fatores biológicos e culturais em constante interação na determinação do fenômeno. Dentre os fatores culturais destacam-se as diferenças de gênero que atuam demarcando papéis de homens e mulheres na sociedade.

Partindo da descoberta de que o pai passa a desempenhar mais de uma função ou papel no contexto familiar como, por exemplo, companheiro, cuidador, protetor, modelo, professor entre outros, pode-se falar que existem diferenças e também similaridades entre pai e mãe, no sentido que, tanto o pai quanto a mãe exercem papéis cruciais no desenvolvimento infantil. Ambos participam tanto da família como da criação dos filhos, mas existem funções e papéis que se diferenciam de acordo com aspectos como, a estrutura da família a cultura e a sociedade. Assim, relata-se a importância de ambos (pai e mãe) como sujeitos ativos e participantes de um contexto cultural que influenciam o desenvolvimento infantil.

Para contribuir com o conhecimento a cerca do desenvolvimento infantil, sobre o envolvimento materno, existem diversos estudos que explicam a sua relação. O que interessa é considerar a existência e a importância do envolvimento paterno com as crianças. $O$ pai não deve ser excluído da responsabilidade de cuidar da criança, precisa, portanto, de incentivo e espaço para desenvolver seu papel. A questão centra-se em buscar entender como o homem vem se adaptando às transformações e definir a paternidade na atualidade. 


\section{Referências bibliográficas}

ALVARENGA, P. \& PICCININI, C. O impacto do temperamento infantil, da responsividade e das práticas educativas maternas nos problemas de externalização e na competência social das crianças. Psicologia: reflexão e crítica, v.20, n. 2, p. 314-23. 2007.

BANDEIRA, M.; GOETZ, E.R.; VIEIRA, M.L. \& PONTES, F.A.R. O cuidado parental e o papel do pai no contexto familiar. In: PONTES, F.A.R.; MAGALHÃES, W.L.B.; BRITO, R.C.S. \& MARTIN, W.L.B. (Orgs). Temas pertinentes à construção da psicologia contemporânea. Belém-Pará: UFPA, 2005. p. 191-230.

BANDEIRA, T.T. A. Crenças sobre investimento parental. Dissertação de Mestrado em Psicologia. Universidade do Estado do Rio de Janeiro, Rio de Janeiro, 2009.

BORRIONE, R.T.M. \& LORDELO, E.R. Escolha de parceiros sexuais e investimento parental: uma perspectiva desenvolvimental. Interação em Psicologia, v.9, n.1, p. 35-43. 2005.

BUCHAN, J.C.; ALBERTS, S.C.;SILK, J. B. \& ALTMANN, J. True paternal care in a multi-male primate society. Nature, v. 425, p. 179-81. 2003.

CERVENY, C.M.O. Pensando a família sistemicamente In: CERVENY, C.M.O. \& BERTHOUD, C.M.E. Visitando a família ao longo do ciclo vital. São Paulo: Casa do Psicólogo, 2002. p. 15-27.

DESSEN, M.A. \& SILVA NETO, N.A. Questões de família e desenvolvimento: a prática de pesquisa (Editorial). Psicologia: teoria e pesquisa, v.16, n. 3, p. 191-92. 2000.

DEVREUX, A.M. A paternidade na França: entre igualização dos direitos parentais e lutas ligadas às relações sociais de sexo. Sociedade e Estado, Brasília, v. 21, n.3, p. 607-24. 2006.

FLECK, A.C. \& WAGNER, A. A mulher como a principal provedora do sustento econômico familiar. Psicologia em estudo, Maringá, v. 8 (num esp), p. 31-8. 2003.

GOETZ, E.R. \& VIEIRA, M.L. Diferenças nas percepções de crianças sobre cuidado parental real e ideal quando pais vivem juntos ou separados. Psicologia: reflexão e crítica, v. 21, n. 1, p. 83-90. 2008. 
GOETZ, E.R. \& VIEIRA, M.L. Percepções dos filhos sobre aspectos reais e ideais do cuidado parental. Estudos de Psicologia, Campinas, v.26 n. 2, p.195203, Abril-Junho de 2009.

GUERRA, R.F. Uma análise evolucionária da parturição e do desenvolvimento infantil em mamíferos. Revista de Ciências Humanas, Florianópolis, n.34, p.395$439,2003$.

HEWLETT, B.S. Father-child relations: cultural and biosocial contexts. NewYork: Aldine De Gruyter, 1992.

INSTITUTO BRASILEIRO DE GEOGRAFIA E ESTATÍSTICA - IBGE, 2006. Disponível em: www.ibge.gov.br/censo

JABLONSKI, B. Paternidade hoje: uma metanálise. In: P. SILVEIRA (Org.). O exercício da paternidade. Pp. 21-128. Porto Alegre: Artes Médicas, 1998.

KASSOTAKI, K.M. Understanding fatherhood in Greece: father's involvement in child care. Psicologia: teoria e pesquisa, v.16, n. 3, p. 213-19. 2000.

KELLER, H. \& CHASIOTIS, A. Maternal investment. In: C.A. SALMON \& T.K. SHACKELFORD (Eds.), Family relations: an evolutionary perspective. Pp. 96-111. Oxford: Oxford University Press. 2007.

KELLER, H. Cultures of infancy. Hillsdale, NJ; Lawrence Erlbaum Associates. 2007.

KRIEGMAN, D. Parental involvement, sexual selection, and evolved mating strategies: implications for psychoanalysis. Psychoanalytic Psychology, 16, 528-53. 1999.

LORDELO, E.R.; FRANÇA, C.B.; LOPES, L.M.S.; DACAL, M.P.O.; CARVALHO, C.S.; GUIRRA, R.C. \& CHALUB, A.A. Investimento parental e desenvolvimento da criança. Estudos de Psicologia, v. 11, n.3, p. 257-64. 2006.

MAGILL-EVANS, J; HARRISON, M.J.; REMPEL, G.; SLATER L.. Interventions with fathers of young children: systematic literature review. Journal of advanced nursing, v. 55, n. 2, p. 248-64. 2006.

PERUCCHI, J. \& BEIRÃO, A.M. Novos arranjos familiares: paternidade, parentalidade e relações de gênero sob o olhar de mulheres chefes de família. Psicologia Clinica v.19, n. 2, p.57-69, 2007. 
PICCININI, C.A.; MOURA, M.L.; RIBAS, A.F.P.; BOSA, C.A.; OLIVEIRA, E.A.; PINTO, E.B.; SCHERMANN, L. \& CHAHON, V.L. Diferentes Perspectivas na Análise da Interação Pais-Bebê/Criança. Psicologia: reflexão e crítica, v.14, n. 3, p. 469-85. 2001.

PIOVANOTTI, M.R.A. Crenças maternas sobre cuidado parental e metas de socialização infantil. Dissertação de Mestrado em Psicologia. Universidade Federal de Santa Catarina. Florianópolis, 2007.

QUINLAN, R.J.; QUINLAN, M.B. \& FLINN, M.V. Parental investment and age at weaning in a Caribbean village. Evolution and Human Behavior, v. 24, p. 1-16. 2003.

ROGOFF, B. A natureza cultural do desenvolvimento humano. Porto Alegre: ArtMed. 2005.

RENON M.C. O princípio da dignidade da pessoa humana e sua relação com a convivência familiar $e$ o direito ao afeto. Dissertação de Mestrado em Direito. Universidade Federal de Santa Catarina, Florianópolis, 2009.

RUELA, S.F. Um estudo Intergeracional de crenças valorizadas por mães em uma comunidade rural do estado do Rio de Janeiro. Dissertação de Mestrado em Psicologia Social. Universidade do Estado do Rio de Janeiro, Rio de Janeiro, 2006.

SACHETTI, V.A.R. Um estudo das crenças maternas sobre cuidados com crianças em dois contextos culturais do Estado de Santa Catarina. Dissertação de Mestrado em Psicologia. Universidade Federal de Santa Catarina, Florianópolis, 2007.

SARAFF, A. \& SRIVASTAVA, H.C. Pattern and determinants of paternal involvement in childcare: an empirical investigation in a metropolis of India. Population Research and Policy Review, v. 29, n. 2, p. 249-73, 2010.

SEIDL DE MOURA, M.L.; RIBAS Jr., R.C.; PICCININI, C.A.; BASTOS, A.C.; MAGALHÃES, C.M.C.; VIEIRA, M.L.; SALOMÃO, N.M.R.; SILVA, A.M.P.M. \& SILVA, A.K.. Conhecimento sobre desenvolvimento infantil em mães primíparas de diferentes centros urbanos do Brasil. Estudos de Psicologia, v. 9, n. 3, p. 421-29, 2004.

SEIDL DE MOURA, M.L. \& RIBAS, A.F.P. Evolução e desenvolvimento humano. In: E. OTTA \& M.E. YAMAMOTO (Eds.). Psicologia evolucionista. Pp. 78-85. Rio de Janeiro: Guanabara Koogan, 2009. 
SILVA, M.R. Sentimentos sobre a paternidade e envolvimento de pais que residem e pais que não residem com seus filhos. Dissertação de Mestrado em Psicologia. Universidade Federal do Rio Grande do Sul, Porto Alegre, 2003.

SILVA, M.B.O. \& BRITO, R.C.S. Breve história das origens da maternidade sob uma perspectiva evolucionista. In: PONTES, F.A.R.; MAGALHÃES, W.L.B.; BRITO, R.C.S. \& MARTIN, W.L.B. (Orgs.). Temas pertinentes à construção da psicologia contemporânea. Pp. 15-39. Belém: UFPA, 2005.

SILVA, M.R. \& PICCININI, C.A. Sentimentos sobre a paternidade e o envolvimento paterno: um estudo qualitativo. Estudos de Psicologia I Campinas, v. 24 , n. 4 , p. 561-73. 2007.

TAHON, M.B. Paternidade, maternidade e cidadania: questões atuais no quadro canadense. Sociedade e Estado, Brasília, v. 21, n. 3, p. 625-642. 2006.

TOKUMARU, R.S. \& BERGAMIN, M.P. Uma abordagem evolucionista das relações pais-filhos e padrastos-enteados. In: GARCIA, A. (Ed.), Relacionamento interpessoal: olhares diversos. Pp. 29-40. Vitória: GM Gráfica e Editora, 2005.

TRIVERS, R.L. Parental investment and sexual selection. In: B. Campbell (Ed.). Sexual selection and the descent of man. Pp. 136-79. Chicago: Aldine Press. 1972.

VIEIRA, M.L. \& PRADO, A.B. Abordagem evolucionista sobre a relação entre filogênese e ontogênese no desenvolvimento infantil. In: SEIDL DE MOURA, M.L. (Org.). O bebê do século XXI e a psicologia em desenvolvimento. Pp. 155-204. São Paulo: Casa do Psicólogo, 2004.

VIEIRA, M.L.; RÍMOLI, A.O.; PRADO, A.B. \& CHELINI, M.O. Cuidado e responsividade parentais: uma análise a partir da teoria da história de Vida e da Teoria do Investimento Parental. In E. OTTA \& M.E. YAMAMOTO (Eds.), Psicologia evolucionista. Pp. 86-95. Rio de Janeiro: Guanabara Koogan, 2009.

WAGNER, A.; PREDEBON, J.; MOSMANN, C. \& VERZA, F. Compartilhar tarefas? papéis e funções de pai e mãe na família contemporânea. Psicologia: teoria e pesquisa, v.21, n. 2, p. 181-86. 2005. 